Д-р техн. наук М.I. Капіца, aсn. Д.М. Кислий

(Дніпропетровський нащ. ун-т залізнич. тр-ту ім. В. Лазаряна)

\title{
ВИЗНАЧЕННЯ ТРИВАЛОСТІ ВИБІГУ ЛОКОМОТИВА ПРИ ПЕРЕХОДІ 3 РЕЖИМУ ТЯГИ В РЕЖИМ ГАЛЬМУВАННЯ
}

Вступ. Під час ведення поїзда по дільниці в ряді випадків здійснюється перехід 3 режиму тяги в режим гальмування. Наприклад, при підході до місця, що вимагає зниження швидкості або зупинки, при виході на шкідливий спуск та ін. Зазвичай при такому переході на певному інтервалі шляху електровоз рухається в режимі вибігу. Відомо, що збільшення довжини пройденого шляху в режимі вибігу призводить до зниження витрати електроенергії і разом 3 тим до збільшення часу ходу. Таким чином, у зазначених випадках має місце протиріччя: зниження витрати електроенергії призводить до небажаного зменшення швидкості руху, i навпаки, прагнення до підвищення швидкості руху викликає збільшення витрати електроенергії.

Аналіз останніх досліджень. При виконанні тягових розрахунків на підставі Правил тягових розрахунків [1], за методом максимуму, не передбачається переміщення поїзда в режимі вибігу, що $\epsilon$ наслідком невивченості цього питання. Новітні технології дозволяють зменшити витрати електроенергії на тягу поїздів шляхом використання режимних карт та встановленням систем енергоефективного ведення [2,3]. Різноманітні алгоритми, за якими встановлюється раціональний режим руху, не завжди дозволяють отримати найбільш енергоефективний режим руху поїзда.

Метою статті є спроба встановити величину раціональної тривалості вибігу та величини зміни швидкості при переході 3 режиму тяги в режим гальмування при виконанні гальмування до повної зупинки поїзда.

Постановка завдання. Нехай поїзд рухається по деякій дільниці, що має однорідний профіль (рис. 1). Щоб забезпечити зупинку поїзда в заданому пункті (або зниження швидкості до заданої величини), гальмування повинно бути виконане 3 таким розрахунком, щоб швидкість змінювалася по лінії $b c d$. Таким чином, при переході з режиму тяги в режим гальмування без проміжного вибігу швидкість буде змінюватися по лінії $a b c d$, а в разі застосування вибігу - по лінії $a c d$.

Як видно з рис. 1, зменшення витрат електроенергії при застосуванні режиму вибігу відбувається на дільниці $S_{1}=S-S_{2}$. Але при цьому зменшується технічна швидкість на дільниці $A-C$, що призводить до збільшення часу ходу поїзда на всій дільниці.

Збільшення часу ходу поїзда $\Delta t$ на дільниці $A-D$ (рис. 1) із застосуванням вибігу становить

$$
\Delta t=t-t_{1}-t_{2}
$$

де $t$ - час руху в режимі вибігу на дільниці $A-C(S)$;

$t_{1}$ - час руху в режимі тяги на дільниці $A-B\left(S_{1}\right)$;

$t_{2}$ - час руху в режимі гальмування на дільниці $B-C\left(S_{2}\right)$. 


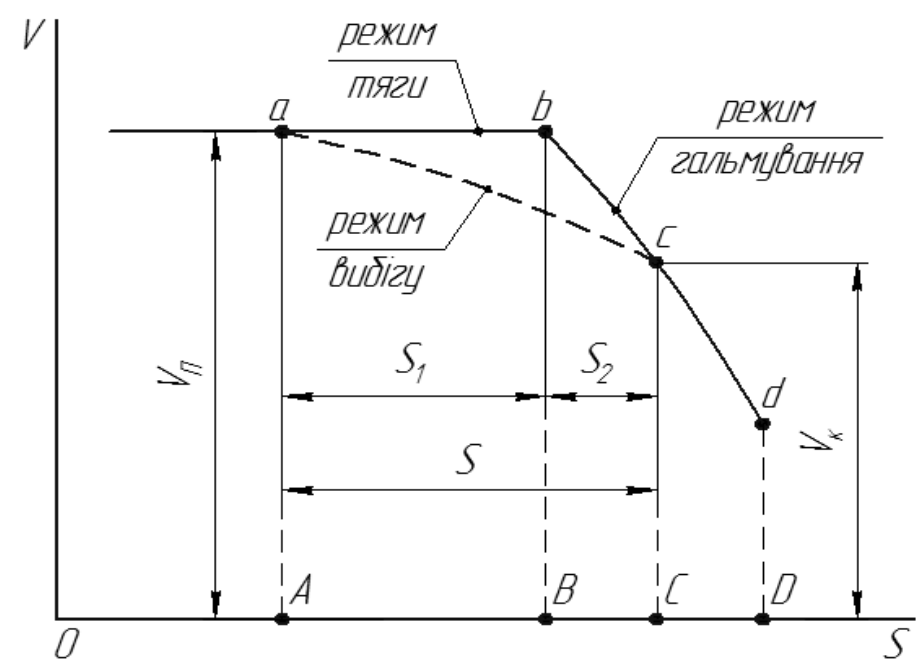

Рис. 1. Траєкторії руху поїзда із застосуванням різних режимів

Виклад основного матеріалу. Для отримання залежності між зниженням витрат електроенергії та збільшенням часу ходу поїзда виконані тягові розрахунки для різних варіантів вихідних даних:

- зміна початкової швидкості (швидкість в точці $a$, рис. 1$) V_{n}=90 \div 40$ км/год;

- зниження швидкості в режимі вибігу (інтервал швидкості в точках $a-c$, рис. 1) $\Delta V=0 \div 50$ км/год;

- різний профіль дільниці: $i=0 \div 10 \%$.

Розрахунки траєкторії руху поїзда та визначення тягово-енергетичних парамет- рів руху виконувались на ідеальній математичній моделі поїзда як однорідного тіла 3 одним ступенем свободи, яка базується на класичних положеннях теорії локомотивної тяги [1, 4, 5] при зміні швидкості $d V=0,5$ км/год.

Для спрощення розрахунків, а також для узагальнення останніх, як вихідні дані прийнято електровоз ВЛ8 із поїздом вагою 4000 т, який складається із чотиривісних вагонів 3 навантаженням на вісь $q_{o}=15$ т. В результаті було отримано такий вираз для основного питомого опору руху поїзда згідно 3 [1]:

$$
w_{x}=0,966+0,686 \cdot 10^{-2} \cdot v+0,175 \cdot 10^{-3} \cdot v^{2}, \mathrm{H} / \text { кН. }
$$

Для розрахунків прийнято, що службове гальмування відбувається 3 натисненням гальмівних колодок, рівним 1/2 повної сили. При гальмівному коефіцієнтові поїзда $[5,1]$

$$
\vartheta_{p}=\frac{\sigma \cdot \Sigma k_{p}}{Q \cdot g}, \mathrm{H} / \kappa \mathrm{H}
$$

отримуємо таку залежність:

$$
b_{m}=0,5 \cdot 1000 \cdot \vartheta_{p} \cdot \varphi_{\kappa p}, \mathrm{H} / \kappa \mathrm{H} .
$$

При використанні у складі чавунних гальмівних колодок, згідно 3 [1], розрахунковий гальмівний коефіцієнт складе

$$
\varphi_{\kappa p}=0,27 \frac{V+100}{5 \cdot V+100} \text {. }
$$

3 врахуванням (5) і (3) питома сила, що діє на поїзд в режимі гальмування, описується рівнянням 


$$
\omega_{o x}+0,5 \cdot b_{2}=0,966+0,686 \cdot 10^{-2} \cdot v+0,175 \cdot 10^{-3} \cdot v^{2}+\frac{199 \cdot(0,27 \cdot V+27)}{5 \cdot V+100} .
$$

Приклад тягово-енергетичного розрахунку для ухилу $i=0 \%$, початкової швидкості $V_{n}=72$

км/год та зниження швидкості в режимі вибігу $\Delta V=10$ км/год наведено на рис. 2 .

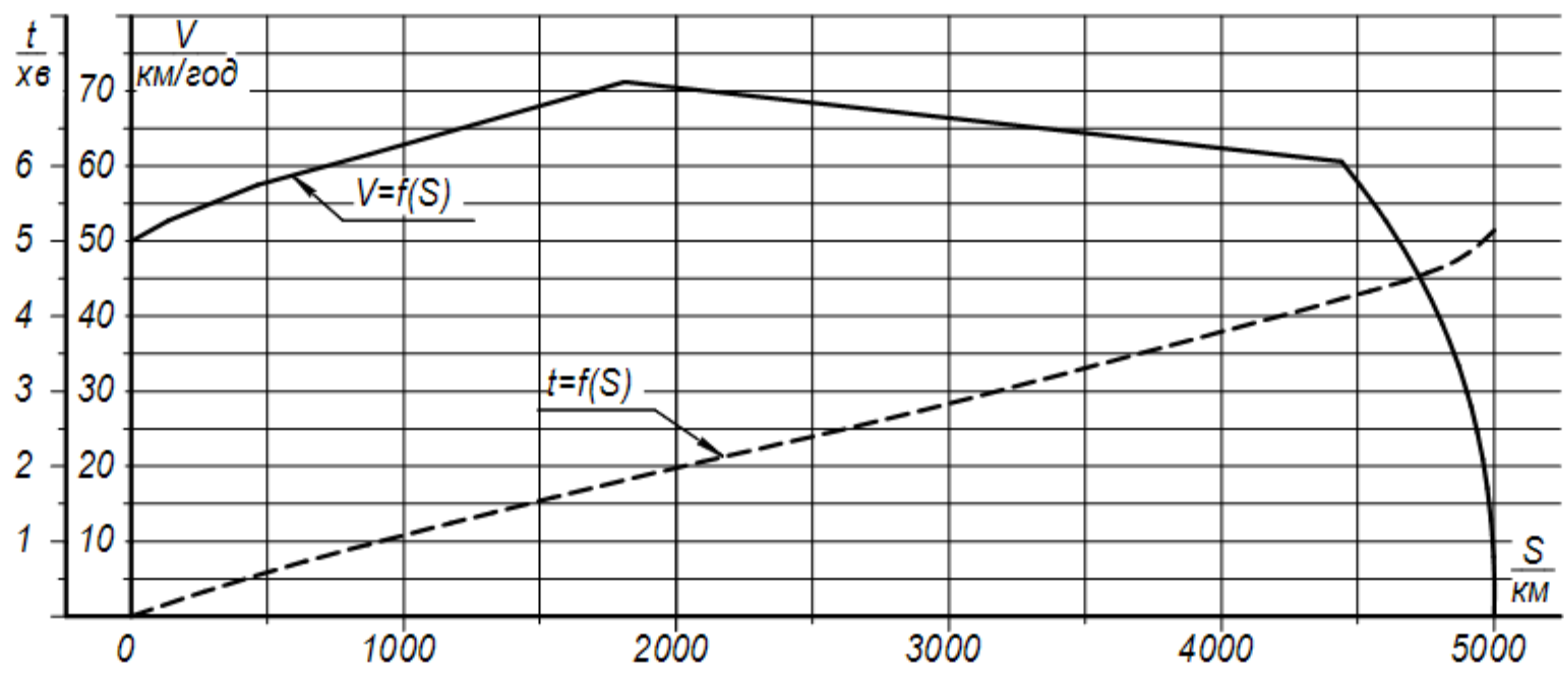

Рис. 2. Приклад тягово-енергетичного розрахунку з використанням математичної моделі

За результатами тягово-енергетичних розрахунків отримані дані про витрату електроенергії $A$ та час ходу поїзда $t$ для різних величин ухилів та зниження швидкостей за час вибігу (таблиця).

Таблиця

Результати тягово-енергетичних розрахунків

\begin{tabular}{|c|c|c|c|c|c|c|c|}
\hline \multirow{2}{*}{$\begin{array}{c}V_{n}, \\
\text { км/год }\end{array}$} & \multirow{2}{*}{$\Delta V$, км/год } & \multicolumn{2}{|c|}{$i=0 \% o$} & \multicolumn{2}{|c|}{$i=5 \%$} & \multicolumn{2}{|c|}{$i=10 \%$} \\
\hline & & $A$, кВт·год & $t, \mathrm{xB}$ & $A$, кВт.год & $t, \mathrm{xв}$ & $A$, кВт·год & $t, \mathrm{xB}$ \\
\hline \multirow{4}{*}{90} & 0 & 138 & 4,27 & 273 & 4,84 & 470 & 5,85 \\
\hline & 5 & 95,5 & 4,31 & 252 & 4,88 & 454 & 5,9 \\
\hline & 25 & - & - & 183 & 5,21 & 416 & 6,12 \\
\hline & 30 & - & - & 167 & 5,33 & 416 & 6,27 \\
\hline \multirow{3}{*}{80} & 0 & 138 & 4,31 & 325 & 5,14 & 559 & 6,51 \\
\hline & 5 & 99,2 & 4,34 & 305 & 5,16 & 544 & 6,5 \\
\hline & 30 & - & - & 219 & 5,63 & 505 & 6,93 \\
\hline \multirow{3}{*}{70} & 0 & 145 & 4,37 & 367 & 5,36 & 634 & 7,03 \\
\hline & 5 & 106 & 4,4 & 347 & 5,37 & 626 & 7,09 \\
\hline & 30 & - & - & 262 & 5,85 & 588 & 7,52 \\
\hline
\end{tabular}


За результатами тягово-енергетичних розрахунків побудовані залежності зниження витрати електроенергії $\Delta A$ від збільшення часу ходу поїзда $\Delta t$ для різних величин початкової швидкості $V_{n}$ переходу в режим вибігу (рис. 3) та різних позитивних ухилів профілю колії (рис. 4).

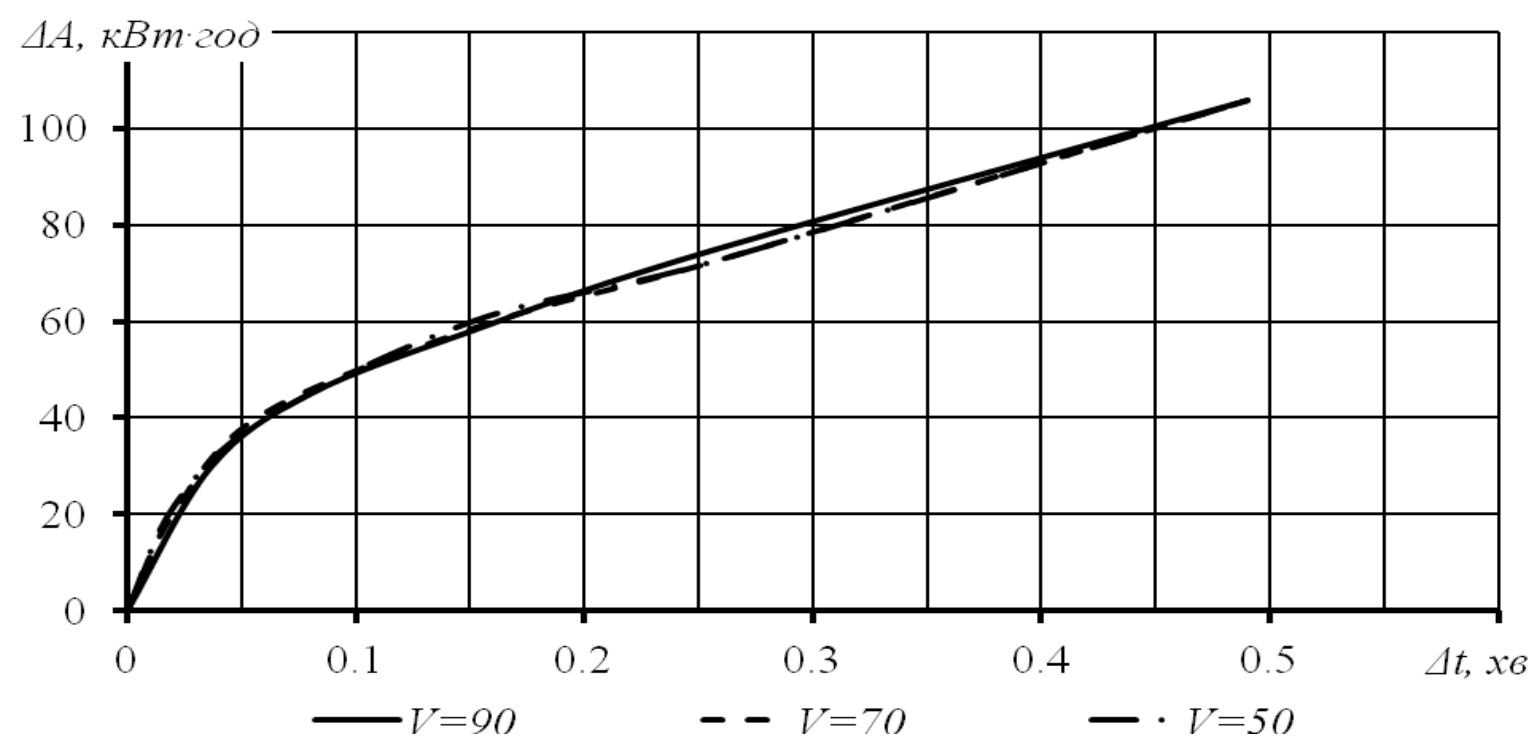

Рис. 3. Залежність зниження витрати електроенергії від збільшення витрати часу при різних швидкостях переходу в режим вибігу та ухилу колії $i=5 \%$

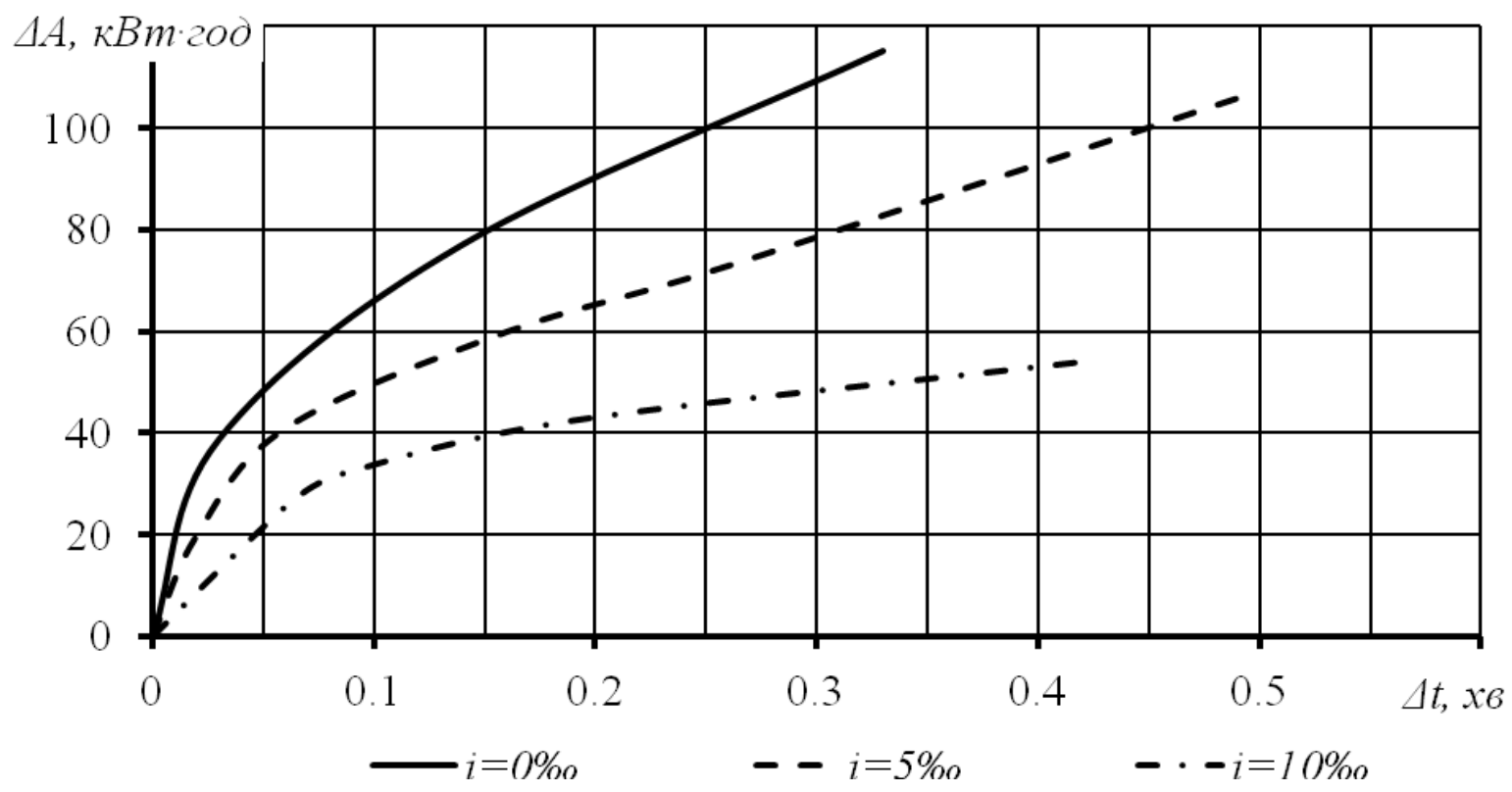

Рис. 4. Залежність зниження витрати електроенергії від збільшення витрати часу при різних ухилах профілю колії для швидкості виходу в режим вибігу $V_{n}=80$ км/год 
Ці залежності являють собою зростаючі функції, що проходять через початок координат та мають такий вираз в кожній точці кривої

$$
\Delta A=a \cdot \Delta t
$$

де $a$ - додатний коефіцієнт, що зв'язує зниження витрати електроенергії та збільшення часу ходу поїзда.

3 виразу (7) визначаємо коефіцієнт $a$, який являє собою відношення витрати енергії $\Delta A$ до збільшення часу ходу $\Delta t$ i вимірюється у кіловатах за годину в 1 хвилину (кВт·год/хв).

$$
a=\frac{\Delta A}{\Delta t}, \text { кВт·год } / \text { хв. }
$$

Цей коефіцієнт можна назвати коефіцієнтом ефективності вибігу. Його величина зростає зі зростанням економії електроенергії та зі зменшенням втрати часу.

На підставі графіка (рис. 3) можна стверджувати, що коефіцієнт ефективності вибігу не залежить від початкової швидкості переходу на режим вибігу, тому для визначення раціональної довжини дільниці або інтервалу зменшення швидкості при прямуванні без струму цей фактор враховувати не будемо. Якщо розглядати залежність (рис. 4), то можна стверджувати, що економія електроенергії 3 використанням проміжного увімкнення режиму вибігу між режимом тяги та режимом гальмування безпосередньо залежить від величини ухилу дільниці.

При зниженні швидкості на $\Delta V=5 \div 10$ км/год в режимі вибігу збільшення часу ходу поїзда вимірюється незначним інтервалом часу, а зниження витрати електроенергії досягає 50 кВт·год.

Зі збільшенням інтервалу зміни швидкості в режимі вибігу збільшується час прямування за рахунок зменшення технічної швидкості на даній дільниці. Спостерігається зниження витрати електроенергії. При значних зниженнях швидкості $(\Delta V>40$ км/год) та малій крутизні підйому збільшення часу ходу може досягати $3 \div 5$ хвилин, а витрата електроенергії знизиться до декількох сотень кіловат-годин.

Для визначення раціональної довжини дільниці або інтервалу зміни швидкості в режимі вибігу згрупуємо результати тягово-енергетичних розрахунків 3 врахуванням вищенаведених висновків та знайдемо середньоарифметичне значення економії електроенергії та збільшення часу ходу поїзда. На підставі отриманих даних будуємо залежності (рис. 5), на яких позначаємо точки інтервалів швидкості в режимі вибігу.

3 врахуванням того, що при малих інтервалах часу $\Delta t$ кут ухилу кривої економії електроенергії більше, ніж при великих інтервалах, то позначимо точки зміни крутизни кривих $\Delta A=f(\Delta t)$. Для крутизни ухилу $i=0 \%$ раціональним буде зменшення швидкості в режимі вибігу $\Delta V=0-(\overline{5} \div \underline{10})$ км/год, для ухилу $i=5 \%$

- $\Delta V=0-(\overline{10} \div \underline{15})$ км/год, для ухилу $i=10 \% \quad-\Delta V=0-(\overline{15} \div \underline{20})$ км/год. Отримані дані наводимо у вигляді графіка (рис. 6).

Для визначення довжини дільниці, на якій доцільно використовувати режим вибігу, скористаємось тяговими розрахунками, результати яких наводимо у вигляді рис. 7.

Перевірку отриманих даних виконано шляхом проведення тягових розрахунків при різних значеннях ваги складу, різних серіях локомотива та профілях дільниці. 


\section{Рухомий склад залізниць}

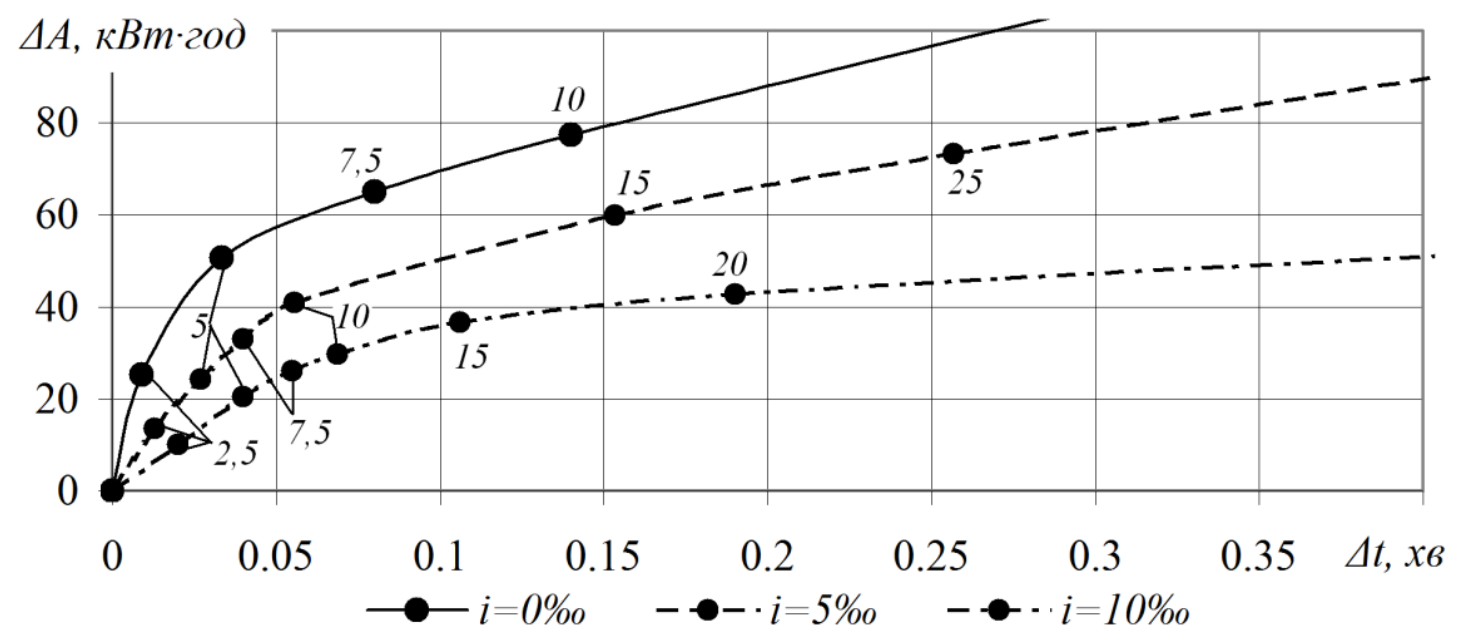

Рис. 5. Залежність зниження витрати електроенергії від збільшення витрати часу при різних ухилах

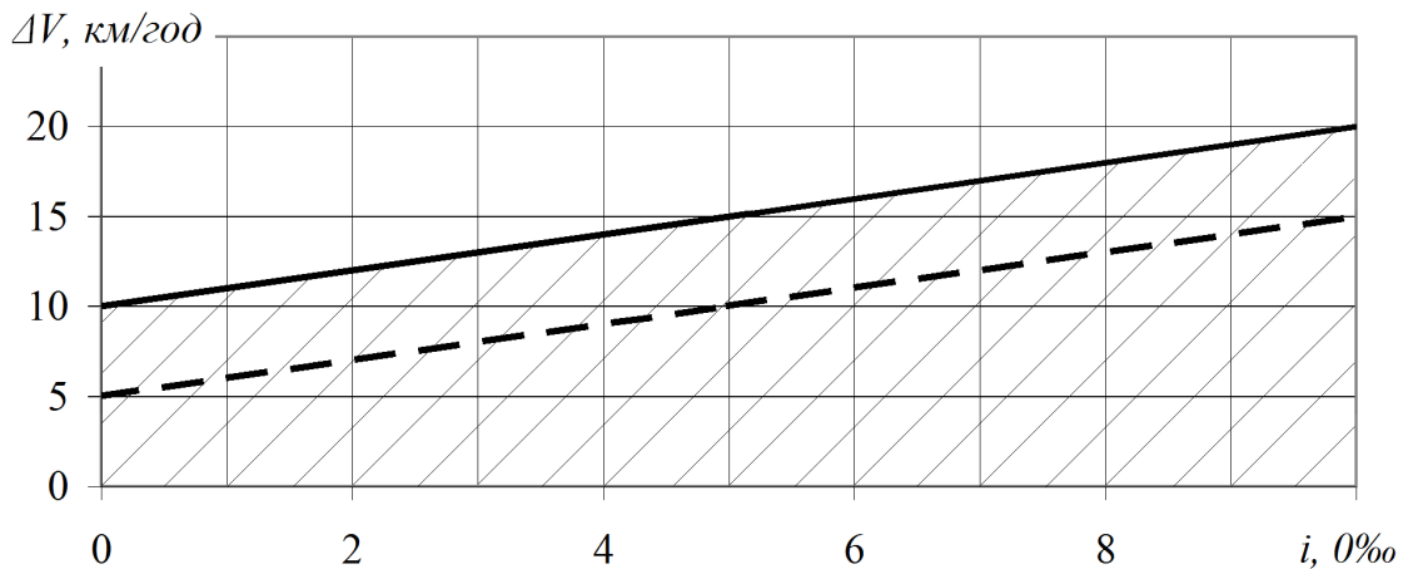

Рис. 6. Раціональний інтервал зміни швидкості в режимі вибігу залежно від ухилу дільниці

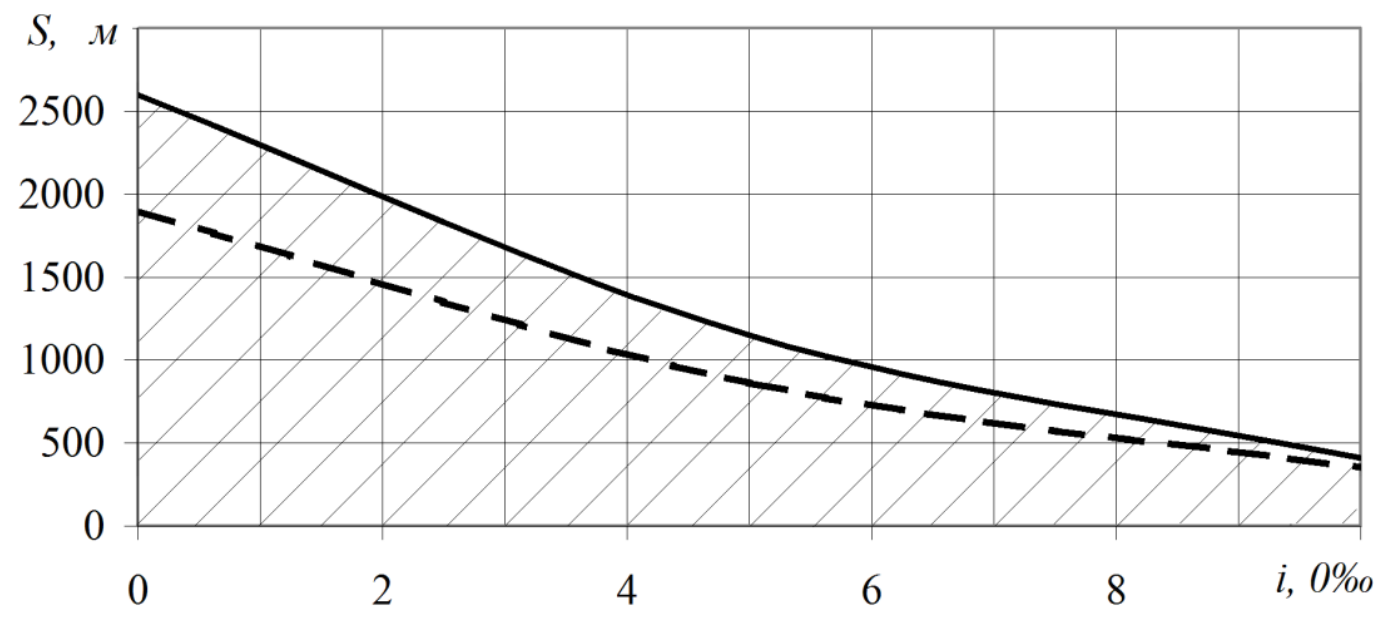

Рис. 7. Раціональна довжина дільниць ходу поїзда в режимі вибігу залежно від ухилу дільниці 
Висновки. На підставі проведеного дослідження можна зробити наступні висновки. Витрата електроенергії та час ходу поїзда залежить в тому числі і від тривалості руху в режимі вибігу між режимом тяги та режимом гальмування. Початкова швидкість виходу з режиму тяги в режим вибігу не впливає на зменшення витати електроенергії. Зниження витрат електроенергії в режимі вибігу безпосередньо залежить від величини ухилу дільниці та інтервалу зміни швидкості. В результаті проведення розрахунків надано значення раціональних інтервалів зміни швидкості та довжини дільниць руху локомотива в режимі вибігу для ефективного використання енергоресурсів для різних ухилів колії.

\section{Список літератури}

1. Правила тяговых расчетов для поездной работы [Текст]. - М.: Транспорт, 1985. $287 \mathrm{c}$.

2. Системы автоведения, регистрации параметров движения и работы тягового подвижного состава [Текст]: обзорное пособие. - М.: ООО «АВП Технология», 2011. - 96 с.

3. Перевезенцев, Е.А. Составы ведут «Автомашинисты» [Текст]/ Е. А. Перевезенцев, А. И. Шемановский// Локомотив-информ// Укр. госуд. акад. ж.-д. трансп. - 2005. - Вып. 6. C. 15-17.

4. Деев, В.В. Тяга поездов [Текст]: учеб. пособие для вузов/ В.В. Деев, Г.А. Ильин, Г.С. Афонин; под общ. ред. В.В. Деева. - М.: Транспорт, 1987. - 264 с.

5. Асадченко, В.Р. Автоматические тормоза подвижного состава [Текст]: учеб. пособие для вузов ж.-Д. транспорта/ В.Р. Асадченко. - М.: Маршрут, 2006. - 392 с.

Ключові слова: режим руху, тягові розрахунки, тяга поїздів, коефіцієнт ефективності вибігу, зниження витрати електроенергії, інтервал швидкості, тривалість вибігу, ухил колії, початкова швидкість.

\section{Анотації}

Витрата електроенергії на тягу поїздів залежить від режиму ведення поїзда. В цій статті питання зниження витрати електроенергії розглянуто з точки зору використання кінетичної енергії поїзда в режимі вибігу локомотива при переході з режиму тяги в режим гальмування. Надано рекомендації щодо керування локомотивом для зменшення витрати електроенергії при незначному збільшенні часу ходу поїзда.

Расход электроэнергии на тягу поездов зависит от режима ведения поезда. В этой статье вопросы снижения расхода электроэнергии рассматриваются с точки зрения использования кинетической энергии поезда в режиме выбега локомотива при переходе из режима тяги в режим торможения. Даны рекомендации по управлению локомотивом для уменьшения расхода электроэнергии при незначительном увеличении времени хода поезда.

Consumption of electricity for traction trains depends on the mode of the train. In this paper the reduction of power consumption is considered from the perspective of the kinetic energy of the train in freewheel mode in the transition from the regime of traction in braking mode. Offered the recommendations for management of the locomotive to reduce power consumption with a slight increase in the time of the train. 